\title{
An E-conversation with Prof. M.M. Sharma
}

\author{
Subhas K. Sikdar ${ }^{1}$
}

Published online: 8 April 2015

(C) Springer-Verlag Berlin Heidelberg (Outside the USA) 2015

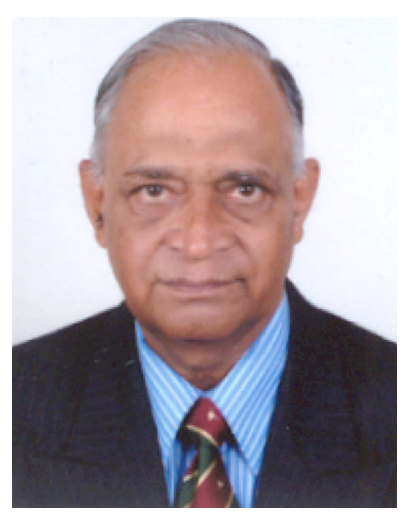

Professor Man Mohan Sharma was educated at Jodhpur (Rajasthan), Mumbai, and Cambridge, England. He was appointed to the rank of Professor in the Institute of Chemical Technology, Mumbai, when he was just above 27 years of age. He was the youngest ever recipient of S.S Bhatnagar prize in Engineering Sciences in 1973. Professor Sharma was elected a fellow of the Indian National Science Academy in 1976 and later became its president during 1989-1990. The crowning glory came in 1990 with his election as a fellow of the Royal Society, England as the first engineer from India to be elected to this august body. Professor Sharma was elected a foreign associate of the US National Academy of Engineering. He also was the Editor of Chemical Engineering Science, and has been a consultant to chemical industry for 50 years.

Subhas K. Sikdar

sikdar.subhas@epa.gov

1 National Risk Management Research Laboratory, EPA, Cincinnati, USA
(Subhas Sikdar): Professor Sharma, Thank you very much for accepting to conduct this conversation with me for this journal. I consider it a special honor to be able to converse with you on matters that span the gamut from science and chemical technologies to what we call progress and the public policy that can shape it. Your entire life has been an inimitable example of technical and pedagogic excellence, and to this day has remained a remarkable inspiration to hundreds of your students and colleagues worldwide. We will traverse those territories shortly, but first I want to engage you in a discussion on sustainability as it relates to the exploits of engineering. As the environmental stewardship dogma moved from waste minimization to pollution prevention to design for the environment eventually arriving at the concept of sustainability, you have had something important to say about all previous concepts through your ideas and research. Given that environmental pollution still is rampant in the Indian cities after all these years of development, I would like to know your ideas of relevance of sustainability to Indian condition and how the country can make significant inroads toward achieving that goal through policy measures, and particularly through the application of cleaner technologies.

(M.M. Sharma): Sustainability is of great importance to India, as it is globally. We should refer to all the so-called waste streams as resource with a negative cost. We can give many valuable examples. Take the case of $\mathrm{SO}_{2}$ from smelter gas which has been valorized as $\mathrm{H}_{2} \mathrm{SO}_{4}$; similarly $\mathrm{H}_{2} \mathrm{~S}$ from sour natural gas and from hydrodesulphurization which has been converted to $\mathrm{S}$ and today a major part of $\mathrm{S}$ is from recovered source. India does not have any sulfur mines.

Active pharmaceutical ingredients (API) in pharma industry provide a fascinating example as India, along with China, has become a leading supplier for global 
consumption. Here typically $10-20$ times the desired product comes out as so-called unwanted waste materials. These provide excellent examples and many units in India are recovering a significant to substantial part of these, what I would like to call co-products. Further, dilution with solvents is typically more than 10 times and unconventional mixed solvents come out and novel methods are needed for recovery and recycle and a lot of success has been realized. Most APIs come through final crystallization and there is always some solubility in the solvent and modern nanofiltration membranes, which can even stand DMF, THF, etc., allow recovery of valuable APIs. Cleaner routes for APIs would be welcome.

India and some other countries, notably Brazil, cultivate sugarcane on a large scale. More than $27 \mathrm{mt}$ per year of sugar is produced in India. Wet bagasse, at a level of about $250 \mathrm{mt}$ per year, from sugar manufacture is fortunately now burnt in co-gen mode and the power thus generated provides a lot of revenue and saves the corresponding amount of fossil fuel. Water balance must be carried out also. Further improvements are expected from drying bagasse with superheated steam that is available in the plant and thus harvest some water as well. The bagasse so saved can go for producing paper and better yet can be converted to good grade alpha cellulose, hemicelluloses, and lignin and all these are value added. This adds to sustainability in a significant way. Molasses should be upgraded to better products like $n$ and isobutanol rather than ethanol. Even blending of ethanol with gasoline should be as ETBE as cat-crackers in refineries produce isobutylene in the C-4 fraction.

A problem of a fairly large magnitude is proper utilization of gypsum/hemi hydrate from phosphoric acid and some chemical plants. It has useful application in cement if the grade is proper and can be used for gypsum boards for housing. However, a real daunting problem is ash from coal-fired power plants and before the end of this decade we in India will be producing $1 \mathrm{mtpd}$. It should have no unburnt carbon to find application in cement industry. We need some innovative technologies to upgrade this resource. This will also require policy change for cement industry. Fluidized bed combustion of even middlings from coal washers allows this resource to be used but smart engineering is required. Here I should like a technology oriented intervention by way of two-stage fluidized bed operation and from the first stage a substantial portion of volatile matter can be recovered and upgraded to transportation fuels. Some coal gasification technologies give liquid products which can be valorized.

Solar energy is coming center stage but we need reduction in capital cost, novel dyes, and cheaper materials.

Recycling of polyethylene and even polypropylene should be done and at least their cracking can be done in fluidized beds to get valuable chemicals and fuels. Used PET bottles provide another opportunity and some part can be converted back to monomers and some for use in surface coating industry.

There is a case for harvesting water in the flue gas when natural gas is burnt; methane contains $25 \mathrm{wt} \%$ by hydrogen. For this some novel technology has to be developed. This will be even more important in water stressed areas. (SKS): One dominant viewpoint of sustainability is of course recycle and reuse of industrial and municipal wastes and focusing on resource use minimization at the front end of any activity. You have correctly focused on this because a part of the wastes becomes pollution in air, water, and land and creates adverse health impacts. The environmental impacts of anthropogenic activities became the genesis of the sustainability movement. You have provided some successful industrial examples of treating wastes as resources, and have also showed some future challenges. It is very tempting to engage in an in-depth discussion on these technical challenges, but this forum being for a different purpose, I will resist. Several questions arise however:

(a) For many reasons, environmental regulations in most developing countries including India work on a piecemeal basis. Do you think that large companies in India are pursuing these sustainability-oriented measures because they think it is good to do these things, or they do it only when it offers economic opportunities, or because environmental regulations are making them become more creative? How about the small and medium size companies? What mechanisms, if any, are available to them?

(b) Is there a real time hope for cleaner air in the big cities in India? I recall that the courts had to get involved in forcing the use of compressed natural gas in buses and taxis in New Delhi. That measure probably helped a little, but New Delhi is still the worse air quality case in India. Is there a technology fix that you see for this problem, and what can be done in the short term? Very similar state of affairs exists in water quality, and similar questions can be asked.

(c) As western companies set up more and more manufacturing in India, they will bring cleaner technologies. I surmise this will help, but I don't know if the relative size of foreign manufacturing is good enough to make a perceptible difference.

(d) The going wisdom these days is that the western countries are outsourcing the manufacturing sector to some developing countries, because technology knowhow, talent pool, and some semblance of infrastructure are present. Perhaps the biggest factor 
is low cost of labor and managerial talent. Is this a big opportunity for India to become a manufacturing giant of the creative kind, like Japan achieved earlier?

\section{(MMS):}

(a) Large companies see clear opportunities in making upstream smarter and believe cleaner and greener is smarter. Enlightened managements see energy conservation as a viable strategy and total recycle beneficial. My personal experiences, spanning five decades, have been most encouraging with large as well as medium size companies. Managements see these endeavors as economically beneficial besides complying with the contemporary regulations. My own view is that we should be ahead of regulations. Take for instance a heavy metal like copper going into a 'waste' stream when it can be an economically attractive proposition to recover via precipitation as copper hydroxide which is saleable fetching good price. In the case of power stations, based on coal, smart burning leading to no unburnt carbon in the ash is economically attractive and ash is suitable for blending with portland cement.

(b) This is a mixed bag as in the case of the two and three wheelers, based on two stroke engine, which are still prevalent, lead to emission of methane, which is undesirable. Further long distance diesel burning trucks which e.g., pass through Delhi, have undesirable emissions. Now diesel has welcome attributes w. r. t. sulfur and aromatics to reduce particulate emissions. However, an Indian city continues to have problems associated with dust, partly because of perpetual construction work. In the cement industry all modern plants do not have particle emissions at all. Water is a very serious problem due to various reasons. It is both due to municipalities and industries and the latter are being tackled e.g., for clean Ganga (also sewage treatment). Technology for water treatment exists but it is a question of implementation.

(c) Multinational corporations (MNC's) have followed all regulations and do indeed conform to requirements as they have pressure from the parent companies. There are many MNC's in India, besides many purely Indian companies, which have total recycle of water. This is making a perceptible difference.

(d) India has proved to be a great and effective partner e.g., in the pharma industry where it has a kind of pivotal position. This is also the case for many other industries e.g., forgings. A very large number of MNC's have $\mathrm{R} \& \mathrm{D}$ centres in India and this includes GE, Shell, SABIC, DSM, Dow, etc.
(SKS): Two central themes of sustainability that we as engineers can do something about are pollution to air, water, and land, and resource conservation through effective process, product, and packaging designs. Continual and measurable improvements can be made in each of these problems. However, many are focusing these days on global warming (called climate change now) due to greenhouse gases such as carbon dioxide, methane, etc., primarily being emitted from coal-fired power plants. According to this understanding, we are heading toward doom with the businessas-usual scenario. I am afraid this issue has become highly politicized. If you were asked to defend the use of coal by China and India to improve the living standards of these two large emitters, how would you profess?

(MMS): The use of coal is indispensable. It will be a long time when renewables like solar and wind will make a sizeable impact. However, it is essential that coal is burnt efficiently and coal gasification is practiced; there is a great scope for underground coal gasification. There is scope in recovering a significant part of the volatile matter of coal and upgrade it to transportation fuels. Nuclear power should get a major boost.

The problem of carbon dioxide emissions is very complicated. Fixation of this emission is far more complicated than is currently thought.

(SKS): Recently I watched a film on your remarkable career on You Tube which featured highlights of your accomplishments as a teacher, researcher, with many of your associates and well-known former students providing testimonials. I was struck by your spirit and enterprise to establish practice-oriented chemical engineering in the University Department of Chemical Engineering (UDCT) at the University of Bombay against what would seem impossible odds. Thanks to your indefatigable courage, Indian chemical engineering benefited immensely. A teacher does not only transfer knowledge but wisdom as well. I am curious to know if you will summarize what ethical values you always intended your students to learn from you.

(MMS): I took up teaching and research at UDCT (now ICT) in spite of handsome offers from USA/Canada/Europe and even India, right in Mumbai, I was acutely aware of the financial stringency in the UDCT and that no PhD had come out of chemical engineering. I was determined to pursue ideas oriented research, with no reference to my work at Cambridge. I also had a mission to develop persons better than myself.

I adhered to ethical values strictly as is evident e.g., from my research students, while pursuing doctoral work, publishing research papers independently in learned journals like Chem Eng Sci, when there were hardly any publications in this journal from India. This was a great moral booster for them. 
I made sure that my interactions with industry followed strict ethical standards. Thus, after my consulting with Tata Chemicals in early the $70 \mathrm{~s}$ I refused to work with any other soda ash manufacturers. There are many other examples. No research student of mine had any delay whatsoever due to my very busy schedules in submitting their thesis.
(SKS): Thank you, Professor Sharma for sharing snippets of your vast accomplishments with us. I am sure the readers of CTEP would be highly delighted to share this story. 